\title{
Probiotics and Periodontal Disease - A Review
}

\author{
Sidharth Shrikant J oshi ${ }^{1}$, Atul A Pandharbale
}

\section{Quick Response Code}

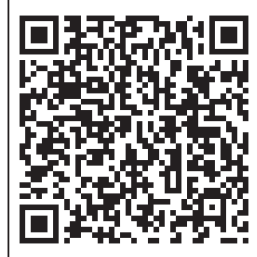

doi: $10.5866 / 2015.7 .10136$

1Postgraduate student

Department of Periodontology,

M. R. Ambedkar Dental College,

1/36, Cline Road, Cooke Town, Bangalore - 560005

2Postgraduate student

Department of Oral Medicine \& Radiology,

Mahatma Gandhi Vidyamandir's,

Karmaveer Bhausaheb Hiray Dental College \&

Hospital,

Mumbai Agra Highway, Panchavati, Nashik 422003

\section{Article Info:}

Received: April 11, 2015

Review Completed: May 11, 2015

Accepted: J une 10, 2015

Available Online: April, 2015 (www.nacd.in)

(C) NAD, 2015 - All rights reserved

\section{Email for correspondence:}

sidharthjsh@rediffmail.com

\begin{abstract}
:
Probiotics are live micro-organisms that when administered in adequate amounts confer health benefits upon the host. A few conventional foods containing probiotics are yogurt, fermented and unfermented milk, soy beverages etc. Most often, they come from two groups of bacteria, Lactobacillus or Bifi dobacterium. Evidence now suggests that probiotics may function not only by direct inhi bition of pathogenicmicro-organisms, but also by more subtlemechanisms including modulation of the mucosal immune system. Little attention has been paid to the identification of beneficial oral bacterial species. Probiotic technol ogy represents a breakthrough approach to maintaining oral health by using natural beneficial bacteria to provide a natural defense against the pathogenic bacteria species. This review endeavours to introduce the concepts of probiotics in periodontics.
\end{abstract}

Key words: Bifi dobacterium, lactobacillus, probiotics

\section{INTRODUCTION}

Bacteria have always been associated with disease and have caused the human race much grief. Hence the concept of harnessing bacteria for health benefits has a poetic ring to it. The concept of beneficial for health micro-organisms dates back to the ideas of Ukrainian Nobel laureate Ilya Metchnikov, working at the Pasteur Institute in Paris, during the early years of 20th century. ${ }^{1}$ The term 'probiotic' is a relatively new word and is currently used to name bacteria with beneficial effects for humans and animals.

The term "probiotics", the antonym of the term "antibiotics", was introduced in 1965 by Lilly and Stillwell as substances produced by microorganisms which promotethe growth of other microorganisms. ${ }^{2}$ The term "probiotics" is derived from the Greek word, meaning "for life." ${ }^{3}$ The use of mi croorganism to promote health is very ancient and can even be traced back to the classical Roman literature where 
food fermented with microorganisms was used as a therapeutic agent. ${ }^{4}$ There is a long tradition, particularly in parts of Europeand Asia, of ingesting microbes or food products that affect the intestinal microbiota in ways that are believed to provide beneficial health effects, i.e. intake of probiotics and prebiotics. $^{5}$

Probiotics, most commonly bel ong to the genera - Lactobacillus and Bifidobacterium. Lactobacillus species from which probiotic strains have been isolated include L. acidophilus, L. johnsonii, L. casei, L. rhamnosus, L. gasseri, and L. reuteri. Bifidobacterium strains include B. bifidum, B. Iongum, and B. Infantis. ${ }^{6}$ Lactobacilli found in raw milk and fermented dairy products such as cheese, yoghurt and fermented milk are ubiquitous in the diet and are found in the gastrointestinal tract soon after birth. ${ }^{7}$ F urthermore, certain strains of Aspergillus, Propionibacterium, Saccharomyces, Streptococcus, Enterococcus and non-pathogenic strain of E.coli, Clostridium butyricum, are among others which have demonstrated probiotics properties. ${ }^{8,9}$

Probiotics can help prevent and treat disease through several mechanisms.

1. Direct interaction: Probiotics interact directly with the disease-causing microbes, making it harder for them to cause the disease.

2. Competitive exclusion: Beneficial microbes directly compete with the disease, developing microbes for nutrition or enterocyte adhesion sites.

3. Modulation of host immuneresponse: Probiotics interact with and strengthen the immune system and help prevent disease. ${ }^{10}$

Given the widespread emergence of bacterial resistance to antibiotics, the concept of probiotic therapy has been considered for application in oral health. Oral probiotics have been evaluated primarily in the management of dental caries. ${ }^{11}$ However there seems to be no reason why probiotic therapy might not also be applicable for controlling the periodontal disease. Taking into account the two major treatment strategies for periodontal disease viz, elimination of specific pathogens and suppression of destructive host response, the probiotic approach may add some value in achieving these treatment goals.

\section{COMPOSITION OF PROBIOTICS}

Probiotics which are regulated as dietary supplements and foods, consist of yeast or bacteria. They are available as capsules, gels, pastes, tablets, packets, liquids, or powders, and are contained in various fermented foods, most commonly yogurt or dairy drinks. Probiotic products may contain a single microorganism or a mixture of several species. Probiotics can be bacteria, moulds, yeast. But most probiotics are bacteria. Among bacteria, lactic acid bacteria are more popular. ${ }^{12}$

\section{MICROORGANISMS USED AS PROBIOTICS} 13,14

\begin{tabular}{lll}
$\begin{array}{l}\text { Lactic acid } \\
\text { producing } \\
\text { bacteria }\end{array}$ & $\begin{array}{l}\text { Non-lactic acid } \\
\text { producing } \\
\text { bacteria }\end{array}$ & $\begin{array}{l}\text { Bifido- } \\
\text { bacterium } \\
\text { species }\end{array}$ \\
\hline L. acidophilus & Bacillus cereus & B. adolescentis \\
\hline L. bulgaricus & Propionibacterium & B. animalis \\
\hline L. casei & Enterococcus faecalisa & B. bifidum \\
\hline L. crispatus & Enterococcus faeciuma & B. breve \\
\hline L. crispatus & Escherichia coli Nissle & B. infantis \\
\hline L. reuteri & Escherichia coli Nissle & B. lactis \\
\hline
\end{tabular}

\section{PROBIOTICS IN ORAL CAVITY}

More than 700 species of oral microbiota have been detected in the human mouth and the resident microbiota of one individual may consist of 30-100 species. ${ }^{9}$ An essential requirement for a microorganism to be an oral probiotic is its ability to adhere to and col onize surfaces in the oral cavity. Studies suggest that lactobacilli as members of resident oral microflora could play an important role in the micro-ecological balance in the oral cavity. The studies further demonstrated that lactobacilli strains with probiotic properties may indeed be found in the oral cavity. Yet there is no evidence whether these lactobacilli strains were detected due to the frequent consumption of dairy products leading to temporary col onization only, or if the oral environment is their permanent habitat. 7,9 


\section{Criteria for Probiotics}

To be considered for use as probiotic following criteria needs to be fulfilled. $7,15,16$

1. It should capable of exerting a beneficial effect on the host animal, e.g. increased growth or resistance to disease.

2. It should be of human origin.

3. It should have high cell viability.

4. It should be non-pathogenic and non-toxic.

5. It should be able to interact or to send signals to immune cells.

6. It should have capacity to influence local metabolic activity

7. It should be capable of surviving and metabolising in the gut environment e.g. resistance to low $\mathrm{pH}$ and organic acids.

8. It should be stable and capable of remaining viable for periods under storage and field conditions.

\section{PROBIOTICS IN PERIODONTAL DISEASE}

Periodontal disease is characterized by the presence of gingival inflammation, periodontal pocket formation, and loss of connective tissue attachment and alveolar bone around the affected teeth. ${ }^{17}$ The current concept concerning the etiology of periodontitis considers 3 groups of factors that determine whether active periodontitis will occur in a subject: a susceptible host, the presence of pathogenic species and the absence of so called "beneficial bacteria". ${ }^{18}$ Taking into account the two major treatment strategies for periodontal disease viz, elimination of specific pathogens and suppression of destructive host response, the probiotic approach may add some value in achieving these treatment goals.

\section{MECHANISMS OF ACTION OF PROBIOTICS}

Probiotics can help prevent and treat disease through several mechanisms including direct interaction, competitive exclusion and modulation of host immune response. The treatment strategies conferred by probiotics against periodontal diseases are mainly anticipated to be either by inhibition of specific pathogens or by altering the host immune response through the following multiple factors, ${ }^{7,15}$, 16

\section{Inhibition of specific organisms}

> Inhibition of pathogen adhesion, colonization and biofilm formation

> Inhibition of pathogen growth by various substances such as organic acids, hydrogen peroxide and bacteriocins against oral pathogens.

\section{Effects on host response}

> Inhibition of collagenases and reduction of inflammation associated molecules

> Induction of expression of cytoprotective proteins on host cell surfaces

> Modulation of pro-inflammatory pathways induced by pathogens

> Prevention of cytokine-induced apoptosis

> Modulation of host immune response

As stated above, a probiotic candidate bacterium should beable to adhereto and successfully establish itself in the oral biofilm to exert health effects. The ability of probiotics to adhere to saliva coated surfaces varies among species and it has been reported that $\mathrm{L}$. rhamnosus and L. paracasei strains possesses strong binding activity. ${ }^{19}$ Recently Haukioja et al haveshown that probiotic Lactobacilli (L. rhamnosus GG, Lactobacillus casei) may affect the oral ecology by specifically preventing the adherence of other bacteria and by modifying the protein composition of the salivary pellicle. Eventually when a species binds well to structures of the oral biofilm, it could be anticipated that this might affect the pathogenic potential of the species based on antimicrobial activity, which infact is another evaluation criterion for probiotics. ${ }^{20} \mathrm{~W}$. cibaria secretes a significant quantity of hydrogen peroxide as well as bacteriocin that acts against gram positive bacteria. This bacterial species has the capacity to coaggregate with Fusobacterium nucleatum and to adhere to epithelial cells. ${ }^{21,22}$ 


\section{Probiotics in Periodontal Disease - An Evidence Based Approach}

Probiotics for periodontal therapy have not been extensively studied. Studies on probiotics and periodontal disease are particularly sparse and at present few clinical studies have evaluated the efficacy of probiotic species from a periodontal disease perspective. Streptococcus oralis and Streptococcus uberis have reported to inhibit the growth of pathogens both in the laboratory and animal models. They are indicators of heal thy periodontium. When these bacteria are absent from sites in the periodontal tissues, those sites become more prone to periodontal disease. ${ }^{23}$ Lactobacillus reuteri and Lactobacillus brevi are among the species able to affect gingivitis and plaque composition positively as well as being specific markers for periodontal disease. ${ }^{24}$

The oral administration of a tablet containing L. salivarius WB21 was able to decrease the plaque index significantly, and the pocket probing depth markedly, in subjects who were smokers. Another finding in this clinical trial was the ability of L. salivarius WB21 to successfully reduce the prevalence of periodontal pathogens. ${ }^{25}$ According to Narva et al, during the fermentation process in milk, Lactobacillus helveticus produces short peptides that act on osteoblasts and increase their activity in bone formation. These bioactive peptides could thereby contribute in reducing bone resorption associated with periodontitis. ${ }^{26} \mathrm{Koll}-\mathrm{K}$ lais et al reported that resident lactobacilli flora inhibits the growth of $\mathrm{P}$. gingivalis and Prevotella intermedia in $82 \%$ and $65 \%$, respectively. ${ }^{27}$ I shikawa et al. observed in vitro inhibition of $P$. gingivalis, $P$. intermedia, and $P$. nigrescens by daily ingestion of L. salivarius in tablet form. ${ }^{28}$

L. acidophilus contained in a tablet named Acilact was first clinically tested by pozharitskaia et al in 1994 and they found improved clinical parameters in periodontitis patients and shifts in local microflora towards gram positive cocci and lactobacilli. Later in the year 2002 Grudianov et al also carried out a clinical study wherethey obtained a probiotic mix in the tablet forms, viz Acilact and
Bifidumbacterin and found normalization of micro flora and reduction of signs of gingivitis and periodontitis. ${ }^{29,30} \mathrm{~A}$ study done by Vivekananda MR using Prodentis lozenges showed plaque inhibition, anti-inflammatory, and antimicrobial effects of Prodentis. The study proposed that probiotics could serve as a useful adjunct or alternative to periodontal treatment when SRP might be contraindicated. ${ }^{31}$

Shimazaki and colleagues, in an epidemiological study found that individuals, particularly nonsmokers, who regularly consumed yoghurt or beverages containing lactic acid exhibited lower probing depths and less loss of clinical attachment than individuals who consumed few of these dairy products. A similar effect was however not observed with milk or cheese. ${ }^{32}$ T wetman et al used L. reutericontaining chewing gum in 42 healthy patients and assessed its effects on crevicular fluid volume, cytokine (interleukin-13, interleukin-6, interleukin10 , and TNF- $\alpha$ ) levels, and bleeding on probing. Crevicular fluid volume, as well as TNF- $\alpha$ and interleukin-8 levels, and bleeding weresignificantly reduced. ${ }^{33}$

A particular concern when evaluating probiotic effects on periodontal disease relates to the means of administration of these bacteria. Generally probiotics are delivered in dairy products (mainly fermented milks), as food supplements in tablet forms or in soft drinks. However these routes of administration cannot provide prolonged contact with oral tissues, facilitating probiotic adhesion to saliva coated surfaces. A lozenge form or chewing gum tablet or gum might better serve the needs for periodontal health prophylaxis. Longitudinal studies are required however to clarify the observed relationship between regular consumption of products containing probiotics and periodontal health.

\section{Guided Pocket Recolonization (GPR)}

Recently, Teughels et al reported that the subgingival application of a bacterial mixture including Streptococcus sanguinis, Streptococcus salivarius (S. salivarius), and Streptococcus mitis after scaling and root planing significantly 
suppressed the re-colonization of Porphyromonas gulae (canine $P$. gingivalis) and P.intermedia in a beagle dog model. Animal study performed to test the concept of bacterial replacement therapy in the treatment of plaque related periodontal disease, this study assessed quantitative changes in the subgingival microbiota after root planing when beneficial bacteria were applied adjunctively. Although application of beneficial bacteria did not exclude pathogen recolonization, it did delay the recolonization process significantly. ${ }^{34}$

In another animal study evaluated radiologically the impact of replacement therapy by monitoring bone density changes and alveolar bone level in periodontal pockets in a dog model. The bone density within periodontal pockets treated with beneficial bacteria improved significantly after 12 weeks, there was a significant increase in the bone level at theend of the study for the pockets receiving beneficial bacteria, and no significant changes were noted in the control pockets. ${ }^{35}$ This novel approach of Guided Pocket Recolonization may provide a valuable addition or alternative to the armamentarium of treatment options for periodontitis.

\section{Safety Aspects of Probiotics}

Increased probiotic supplementation of different food products during the recent years has raised safety concerns. When probiotics are applied orally, at least a part of them will be ingested and can interact with a patients systemic health. When ingested orally, probiotics are generally considered safe and well tolerated with bloating and flatulence occurring frequently. ${ }^{8}$ The increased probiotic consumption inevitably leads to increased concentrations of these species in the host organism. Although rare, cases of probiotics-related bacteraemia, lactobacillus endocarditis and liver abscess secondary to $\mathrm{L}$. rhamnosus have been reported in the literature and such cases have responded well to appropriate antibiotic therapy. Recently, major and minor risk factors for probioticsassociated sepsis have been identified. Major risk factors include immunosuppression (including a debilitated state or malignancy) and prematurity in infants. ${ }^{9}$ Although administration of probiotics generally can be considered safe, each strain of probiotics has specific properties that should be considered before its use in any patient.

\section{CONCLUSION}

Probiotics represent a new area of research in periodontal therapy. Probiotics play an important role in combating issues with overuse of antibiotics and antimicrobial resistance. Today.s new technological era would be the right time to change the way bacteria are treated. Clinical trials should be directed to assess the method of probiotic administration in oral cavity and dosages for different therapeutic uses. Studies have been largely conducted in animals, and human studies have not been of sufficient duration to assess the impact on periodontal disease. Much more scientific developments are needed to have a better understanding of these tiny forms of lives in order to broaden their potential applications.

\section{REFERENCES}

1. Rinkee Mohanty, Bianca Nazareth, Neha Shrivastava. The potential role of probiotics in periodontal health. RSBO 2012; 9(1):85-87.

2. Tanboga I, Caglar E, Kargul B. Campaign of probiotic food consumption in Turkish children, oral perspectives, Probiotics for your child. Int J Pediatr Dent 2003; 13:59-64.

3. Hamilton-Miller J MT, Gibson GR, Bruck W. "Some insights into the derivation and early uses of the word "probiotic". Br J Nutr 2003; (90):845.

4. Report of a J oint FAO/WHO Expert consultation on evaluation of health and nutritional properties of probiotics in food including powder milk with live lactic acid bacteria 2001.

5. Shivakumar V, Pavithra Priyadharshoni S, Gopinath V. Probiotics in Periodontology. Ind J Multidis Dent 2011; 1(6):315-320.

6. Suvarna VC, Boby VU. Probiotics in human health: A current assessment. Current Science 2005; 88:1744-1788.

7. Stamatova I, Meurman J H. Probiotics and periodontal disease. Periodontol 2000 2009; 51:141-151.

8. Chatterjee A, Bhattacharya $\mathrm{H}, \mathrm{Kandwal} A$. Probiotics in periodontal health and disease. J Indian Soc Periodontol 2011; 15(1):23-28.

9. Meurman J H, Stamatova I. Probiotics: contributions to oral health. Oral Dis 2007; 13(5): 443-451. 
10. Aas J A, Paster BJ, Stoles LN, Olsen I, Dewhirst FE. Defining the normal bacterial flora of the oral cavity. J Clin Microbiol 2005; 43:5721-5732.

11. Deepa D, Mehta S. Is the role of probiotics friendly in thetreatment of periodontal diseases !!J Ind Soc Perio 2009; 13(1):30-1.

12. Ahola AJ, Yli-Knuuttila $H$, Suomalainen $T$, Poussa $T$, Ahlstrom A, Meurman J H, Short term consumption of probiotic containingcheese and its effect on dental caries risk factor. Arch Oral Biol 2002; 47:799-804.

13. Suvarna VC, Boby VG. Probiotics in human health. A current assessment. Current Science 2005; 88: 1744-1748.

14. Senok AC, Ismaeel AY, Botta GA. Probiotics: facts and myths. Clin Microbiol Infect 2005; 11(12): 958-966.

15. Santosa S, Farnworth E, J ones PJ. Probiotics and their potential health claims. Nutr Rev 2006; 64(6):265-274

16. Mackay AD, Taylor MB, Kibbler CC, Hamilton-Miller J M. Lactobacillus endocarditis caused by a probiotic organism. Clin Microbiol Infect 1995; 5:290-292.

17. Reid G, J ass J, Sebulsky MT, McCormick J K. Potential uses of probiotics in clinical practice. Clin Microbiol Rev 2003, 16(4):658-672.

18. Listgarten MA. Pathogenesis of Periodontitis. J Clin PeriodontoL 1986; 13(5):418-430.

19. Haffajee AD, Socransky SS. Microbial etiological agents of destructive periodontal diseases. Periodontol 2000 1994; 5:78-111.

20. Haukioja A, Yli-Knnuttila H, Loimarranta V, Kari K. Oral adhesion and survival of probiotic and other lactobacilli and bifidobacteria in vitro. Oral Microbial Immunol 2006; 21:326-332.

21. Haukioja A, Loimaranta V, Tenovuo J . Probiotic bacteria affect the composition of salivary pellicle and streptococcal adhesion in vitro Oral Microbial I mmunol 2008; 23:336-343.

22. Kang MS, Kim BG, Chung J, Lee HC. Inhibitory effect of Weissella cibaria isolates on the production of volatile sulphur compounds. J Clin Periodontal 2006; 33(3):226-232.

23. Srionnual S, Yanagida F, Lin LH, Chen YS. Weisellicin 110, a newly developed bacteriocin from Weisella cibaria110, isolated from plaasom, a fermented fish product from Thialand. Appl Environ Microbiol 2007; 73(7):2247-2250.

24. Hillman J D, Socransky SS, Shivers M. The relationships between streptococcal species and periodontopathic bacteria in human dental plaque. Arch Oral Biol 1985; 30:791-795.
25. Krasse $\mathrm{P}$, Carlsson B, Dahl C, Paulsson A, Nilsson A. Decreased gum bleeding and reduced gingivitis by the probiotic Lactobacillus reuteri. Swed Dent J 2006; 30:55-60.

26. Shimauchi H, Mayanagi G, Nakaya S. Improvement of periodontal condition by probiotics with Lactobacillus salivarius WB21: a randomized double blind, placebo controlled study. J Clin Periodontol 2008; 35:897-905.

27. Narva M, Halleen J, Vaannanen K, Korpela R.Effects of Lactobacillus helveticus fermented milk on bone cells in vitro. Life Sci 2004; 75(14):1727-1734.

28. Koll-Klais P, Mandar R, Leibur E, Marcotte $\mathrm{H}$, Hammarstrom L, Mikelsaar M. Oral lactobacilli in chronic periodontitis and periodontal health: species composition and antimicrobial activity. Oral Microbiol Immunol 2005; 20:354-361.

29. Ishikawa H, AibaY, Nakanishi M, Oh-Hashi Y, KogaY. Suppression of periodontal pathogenic bacteria by the administration of Lactobacillus salivarius T12711. J J ap Soc Periodontol 2003; 45:105-112.

30. Pozharitskaia MM, Morozova LV, Melnichuk GM, Melnichuk SS. The use of the new bacterial biopreparation acilact in the combined treatment of periodontitis. Stomatologia 1994; 73:17-20.

31. Grudianov AI, Dimitrieva NA, Fomenko EV. Use of probiotics Bifidumbacterium and Acilact in tablets in therapy of periodontal inflammation. Stomatologia 2002; 81:39-43.

32. Vivekananda $M R$, Vandana $K L$, Bhat KG. Effect of the probiotic Lactobacilli reuteri (Prodentis) in themanagement of periodontal disease: a preliminary randomized clinical trial. J Oral Microbiol 2010; 2(2):5344.

33. Shimazaki Y, Shirota T, U chida K, Yonemoto K, et al. Intake of dairy products and periodontal disease: the Hisayama study. J Periodontol 2008; 79(1):131-137.

34. Twetman S, Derawi B, Keller M, Ekstrand K, YucelLindberg $T$, Stecksen-Blicks $C$. Short-term effect of chewing gums containing probiotic Lactobacillus reuteri on thelevels of inflammatory mediators in gingival crevicular fluid. Acta Odontol Scand 2009; 67:19-24

35. Teughels W, Newman MG, Coucke W, Haffajee AD, van der Mei HC, Haake SK, et al. Guiding periodontal pocket recolonization: A proof of concept. J Dent Res 2007; 86:10781082.

36. Nackaerts $O, J$ acobs $R$, Quirynen $M$, Rober $M$, Sun $Y$, Teughels W. Replacement therapy for periodontitis: pilot radiographic evaluation in a dog model. J Clin Periodontol 2008; 35(12):1048-1052. 